\title{
Colorectal Sporadic Serrated Polyp
}

National Cancer Institute

\section{Source}

National Cancer Institute. Colorectal Sporadic Serrated Polyp. NCI Thesaurus. Code C96469.

A term that refers to a group of polypoid lesions in the colon and rectum that are characterized by the presence of serrated architecture of the epithelial component. This group includes hyperplastic polyps, traditional serrated adenomas, and sessile serrated adenomas/polyps. 